\title{
Cerebral Venous Thrombosis with Skull Base Osteomyelitis and a Retropharyngeal Mass
}

\author{
Jerry Oommen ${ }^{1}$, Hisham Valiuddin ${ }^{2}$, Hope Ring ${ }^{3}$, and Paul Shotkin ${ }^{3}$ \\ ${ }^{1}$ Michigan State University College of Osteopathic Medicine \\ ${ }^{2}$ Hospital of the University of Pennsylvania \\ ${ }^{3}$ St. Mary Mercy Hospital
}

March 18, 2021

\begin{abstract}
88-year-old male with recent history of mastoiditis status post completing outpatient antibiotic regimen presented with worsening neck pain. Found to have complications of cerebral venous sinus thrombosis, skull base osteomyelitis and a retropharyngeal mass. This is the eleventh case in medical literature reporting on this phenomenon.
\end{abstract}

\section{Hosted file}

Clinical Case Reports FINAL.pdf available at https://authorea.com/users/402233/articles/ 514093-cerebral-venous-thrombosis-with-skull-base-osteomyelitis-and-a-retropharyngealmass 


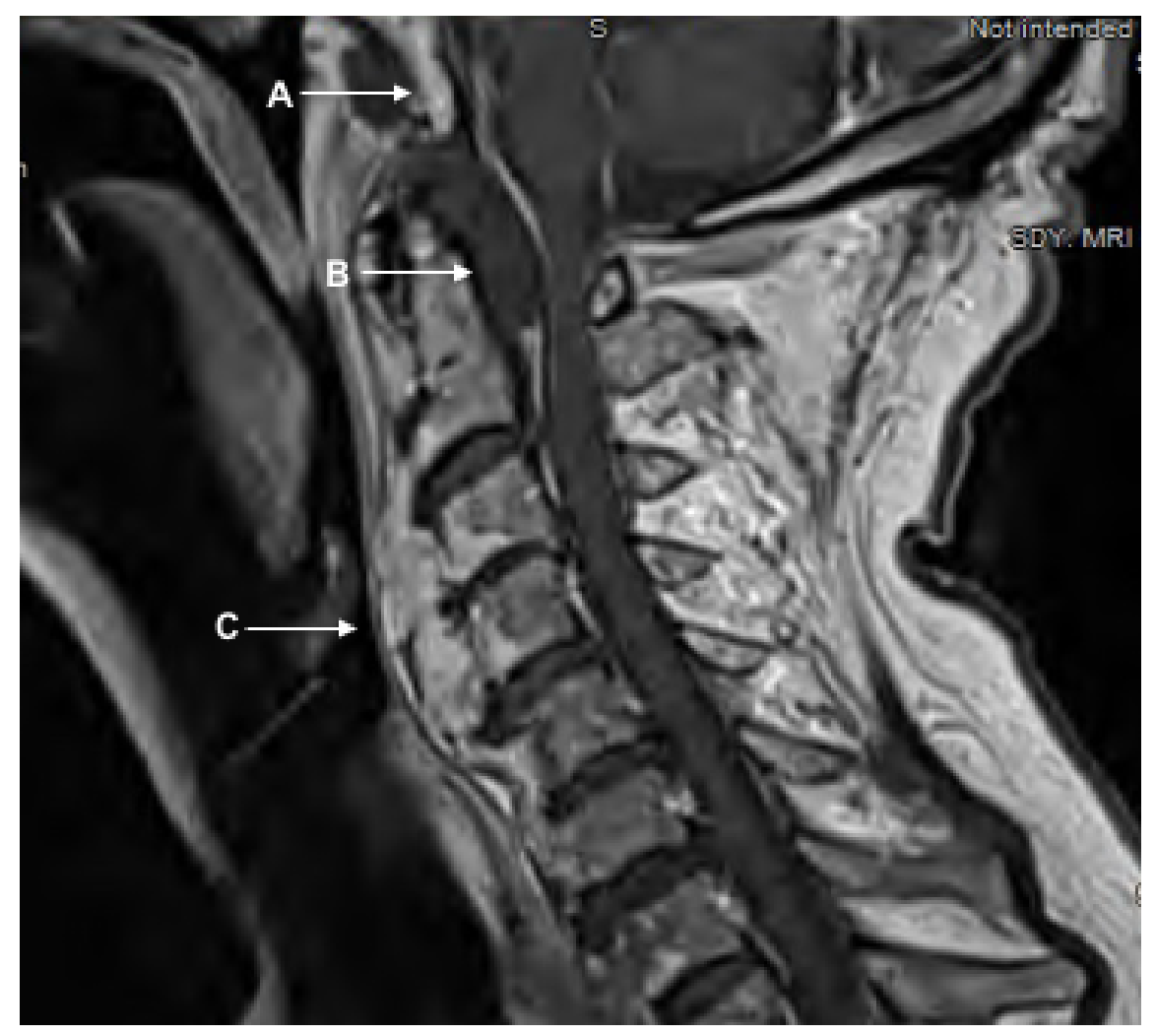




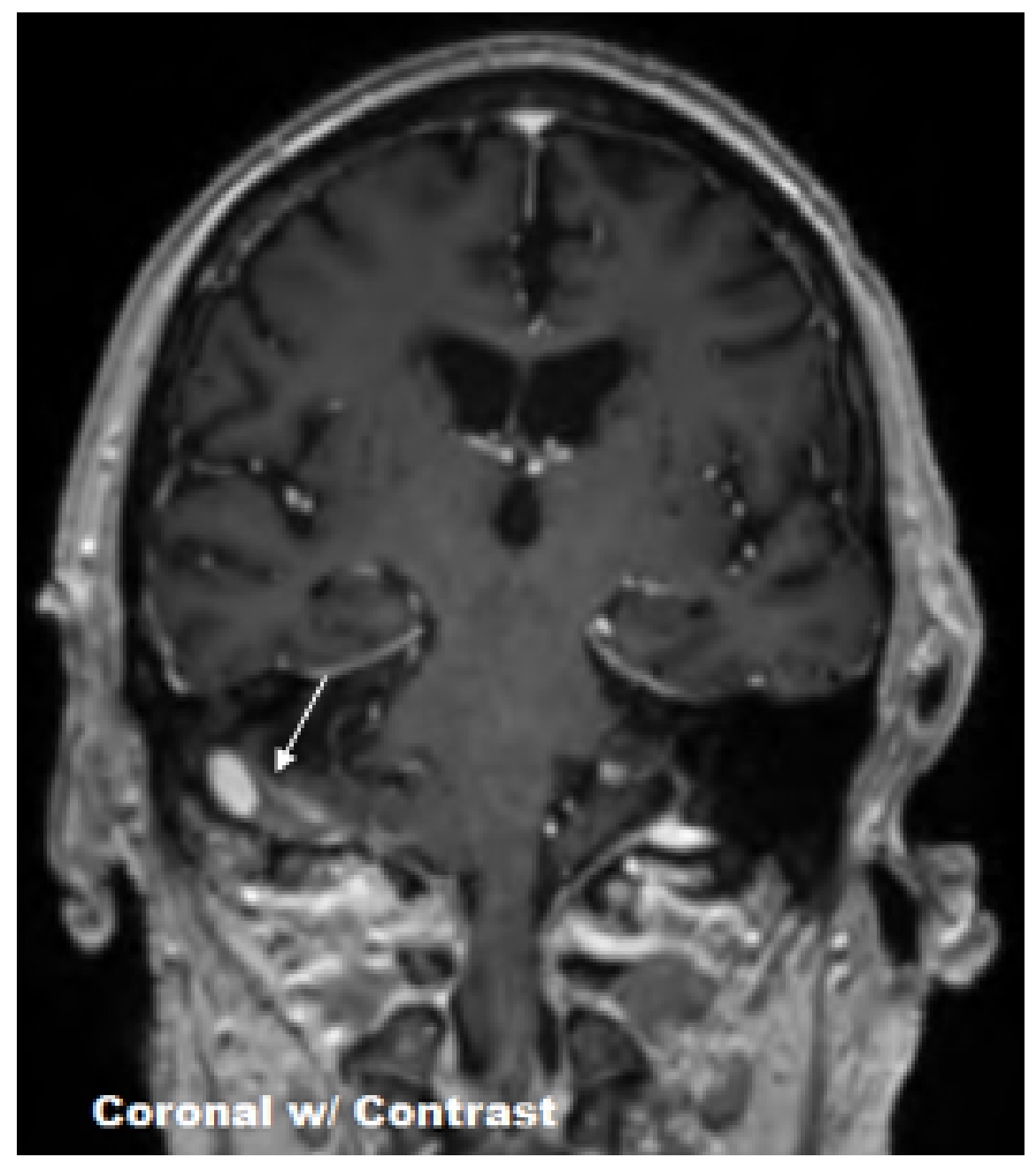




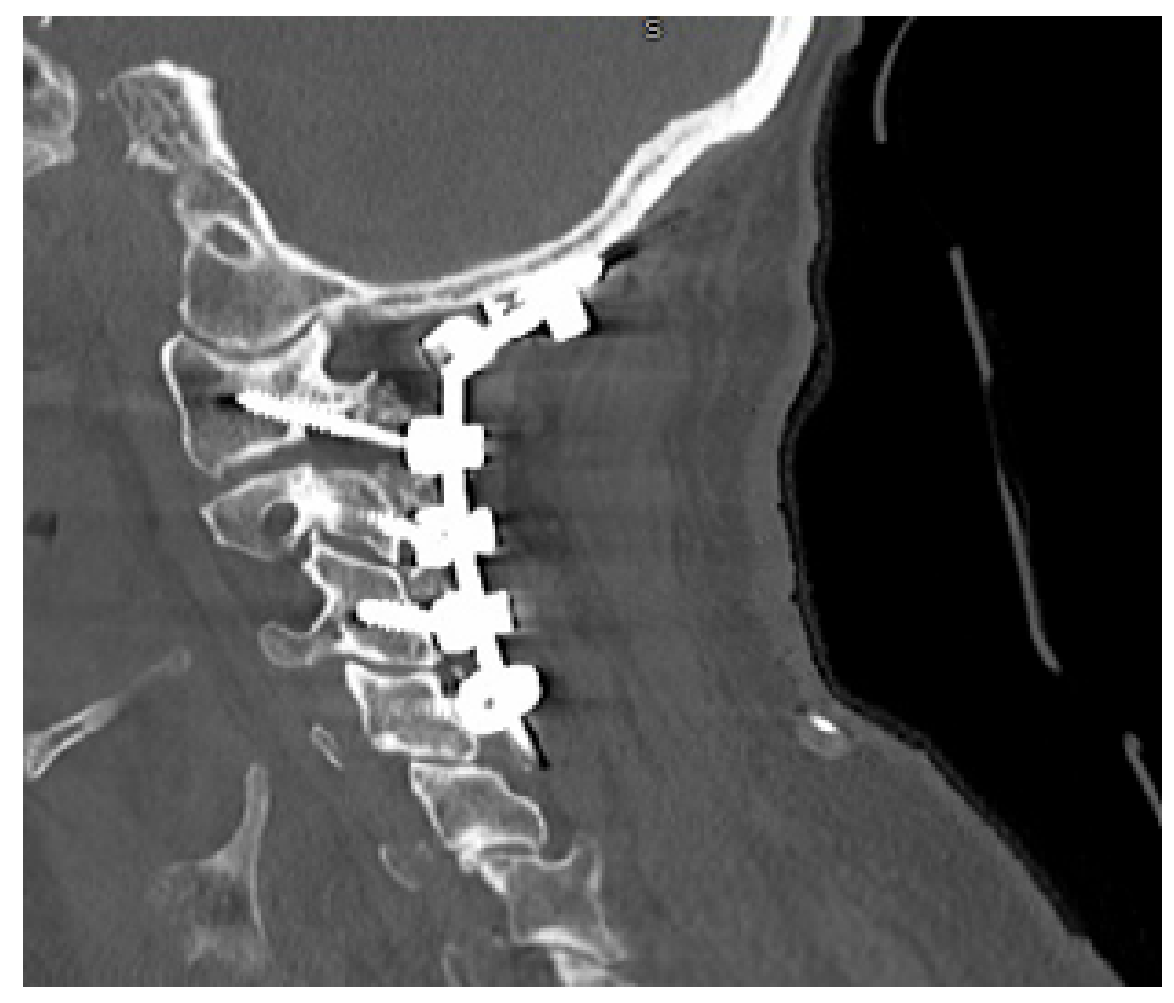

